DOI: https://doi.org/10.47405/mjssh.v6i7.884

\begin{tabular}{|c|c|}
\hline 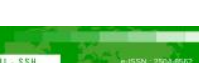 & Malaysian Journal of Social Sciences and Humanities (MJSSH) \\
\hline Malaysian Journal of & Volume 6, Issue 7, July 2021 \\
\hline (MJ-ssH) & e-ISSN : 2504-8562 \\
\hline & $\begin{array}{l}\text { Journal home page: } \\
\text { www.msocialsciences.com }\end{array}$ \\
\hline
\end{tabular}

\title{
Kaedah Humor dalam Pengajaran oleh Guru Bahasa Melayu di Sekolah Rendah : Satu Kajian Fenomenologi
}

Hafifi H. Horace1, Musirin Mosin'1

1Universiti Malaysia Sabah (UMS)

Correspondence: Hafifi H. Horace (hafifihorace@gmail.com)

\begin{abstract}
Abstrak
Penyelidikan ini adalah mengenai kaedah humor dalam pengajaran guru Bahasa Melayu di Sekolah Rendah. Pendekatan kajian yang digunakan adalah menggunakan kajian kualitatif. Manakala reka bentuk kajian adalah fenomenologikal. Instrumen yang digunakan dalam melaksanakan pengumpulan data adalah temu bual separa berstruktur, rakaman audio pengajaran dan analisis dokumen. Pemilihan peserta kajian seramai empat orang adalah secara bertujuan dan berdasarkan kriteria humor yang ditentukan oleh penyelidikan berpandukan kajian-kajian lepas mengenai humor dalam pengajaran. Analisis data telah dilaksanakan dengan menggunakan analisis tematik. Tema-tema yang dihasilkan adalah berdasarkan pengulangan elemen berdasarkan data yang diperoleh melalui hasil analisis dapatan daripada data verbatim para peserta kajian. Hasil kajian menunjukkan bahawa kaedah humor dalam pengajaran oleh peserta kajian adalah sesuai dengan konteks pengajaran Bahasa Melayu dan juga kepada para murid dalam suasana Pengajaran dan Pemudahancaraan Bahasa Melayu. Tema yang muncul daripada elemen dan kategori yang dihimpunkan ialah terdiri daripada tiga tema iaitu kaedah humor secara komunikasi, kaedah humor menggunakan bahan dan kaedah humor secara variasi pengajaran. Kesimpulannya, para peserta kajian menggunakan humor yang bersesuaian dan boleh diterima oleh murid di sekolah rendah. Kaedah humor yang digunakan juga adalah seiring dengan konsep pembelajaran menyeronokkan serta kaedah didik hibur yang ditekankan dalam Kurikulum Standard Sekolah Rendah bagi mata pelajaran Bahasa Melayu. Justeru, dapatan yang diperoleh daripada penyelidikan ini adalah diharapkan untuk dicadangkan sebagai satu panduan pengajaran penggunaan humor dalam pengajaran oleh guru Bahasa Melayu di sekolah rendah bermula daripada pendedahan di peringkat Jabatan Pelajaran Negeri seterusnya di peringkat Pejabat Pendidikan Daerah dan latihan dalaman di peringkat sekolah rendah kelak.
\end{abstract}

Kata kunci: kaedah humor, pengajaran, sekolah rendah, Bahasa Melayu

\section{Humor Methods in Teaching of Malay Language Teachers in Primary Schools: A phenomenological study}

\begin{abstract}
This research is about the method of humor in teaching by Malay Language teachers in primary schools. The research approach used is to use qualitative research. While the study design is Phenomenological. The instruments used in performing data collection were semi -structured interviews, audio recordings of instruction and document analysis. The selection of four study participants was purposeful and based on humor criteria determined by research based on previous studies on humor in teaching. Data analysis was performed using thematic analysis. The themes
\end{abstract}


generated are based on the repetition of elements based on data obtained through the results of analysis of findings from the verbatim data of the study participants. The results showed that the method of humor in teaching by study participants was within the context of teaching Malay Language and also to the students in an atmosphere of teaching and learning of Malay Language. The themes that emerge from the elements and categories that are collected consist of three themes, namely humor method by communication, humor method using materials and humor method by teaching variation. In conclusion, the study participants used humor that was appropriate and acceptable to students in primary school. Methods used humor also is in line with the concept of fun learning methods and Didik Hibur emphasized in the primary school standard curriculum for the Malay Language subject. Thus, the findings obtained from this study are expected to be proposed as a teaching guide using humor in teaching by teachers Malay Languange in primary schools starting from exposure at the State Education Department (JPN) next in the ranking of the District Education Office (PPD) and internal training at primary school level in the future.

Keywords: humor methods, teaching, primary schools, Malay Language

\section{Pengenalan}

Humor merupakan salah satu elemen utama dalam Pembelajaran Menyeronokkan serta Pendekatan Didik Hibur. Perbezaan yang wujud dalam kalangan murid memerlukan guru untuk memilih kaedah pengajaran yang sesuai dengan semua murid tanpa membezakan mereka. Tambahan lagi, implikasi perkembangan drastik dalam sistem Pendidikan merupakan satu cabaran kepada para guru pada masa kini. Oleh hal yang demikian guru perlu memilih kaedah pengajaran yang sesuai dan memudahkan mereka dalam menangani perkara ini. Maka dengan itu, Kementerian Pendidikan Malaysia (KPM) telah menghasilkan satu Konsep Program Transformasi Sekolah 2025 (TS25) yang menumpukan kepada usaha untuk melahirkan modul insan terunggul melalui persekitaran yang menyeronokkan dan penglibatan murid yang aktif lagi bermakna (Amin Senin, 2018). Oleh hal yang demikian, penyelidikan ini adalah menumpukan kepada satu elemen utama dalam konsep pembelajaran menyeronokkan iaitu humor.

Hal ini juga selaras dengan pendekatan yang diperkenalkan oleh KPM sejak 8 Julai 2009 iaitu pendekatan Didik Hibur (Khairuddin et al., 2012). Perkara ini juga turut diterangkan dalam modul didik hibur yang menyatakan bahawa salah satu elemen dalam pendekatan ini ialah elemen humor (Khairuddin et al., 2012; Zailah, 2012). Turut disebut dalam Standard Kualiti Pendidikan Malaysia Gelombang Kedua (SKPMG2), (Jemaah Nazir \& Jaminan Kualiti, 2018) iaitu guru perlu untuk melaksanakan pengurusan kelas yang cekap bagi mewujudkan suasana yang kondusif untuk keberkesanan pengajaran dan pembelajaran. Hal ini diterangkan dalam Borang Penskoran Standard SKPMG2 dalam aspek Guru Sebagai Pengawal iaitu guru perlu mewujudkan suasana pembelajaran yang menyeronokkan mengikut kesesuaian dan keperluan, secara berhemah, menyeluruh dan berterusan.

Hal ini juga telah ditekankan lebih sedekad yang lalu (Jemaah Nazir Sekolah, 2004). Walau bagaimanapun, berdasarkan carian pendekatan pengajaran menggunakan humor oleh penyelidik adalah kurang. Ini kerana kajian mengenai penggunaan humor dalam peringkat sekolah rendah masih terhad (Chaniotakis, 2010; Frymier et al., 2008; Ziv, 1988). Pengkaji tempatan juga menyatakan bahawa masih terdapat segelintir guru yang telah lama berkhidmat menggunakan kaedah tradisional dalam pengajaran Bahasa Melayu (Abdul Rasid \& Shamsudin, 2015). Pernyataan ini disokong lagi dengan kajian Zamri dan Magdeline (2012) yang menunjukkan segelintir guru masih mengajar penulisan Bahasa Melayu dalam keadaan statik dan tidak menyeronokkan. Maka, penyelidikan ini adalah untuk meneroka kaedah humor dalam pengajaran guru Bahasa Melayu di sekolah rendah serta berharap agar dapatan ini dapat dicadangkan sebagai satu panduan pengajaran humor kepada guru Bahasa Melayu serta menambahkan lagi literatur terkini mengenai humor dalam pengajaran Bahasa Melayu khasnya di sekolah rendah. 


\section{Objektif Kajian}

Penyelidikan ini adalah bertujuan untuk meneroka kaedah humor dalam pengajaran Guru Bahasa Melayu di sekolah rendah.

\section{Sorotan Literatur}

Kaedah humor dalam pengajaran oleh guru Bahasa Melayu di sekolah rendah diterangkan melalui Teori Humor yang menjadi sebagai teori utama dalam penyelidikan ini. Teori utama merupakan satu kaedah untuk menerangkan dan memperincikan fenomena yang berlaku dalam sesuatu penyelidikan kualitatif (Othman, 2018). Antara teori-teori yang terdapat dalam teori ini adalah Teori Relief, Teori Superioriti dan Teori Ingkongruiti. Ketiga-tiga teori ini dapat menerangkan fenomena kaedah humor yang digunakan oleh peserta kajian dalam menggunakan humor dalam pengajaran mereka.

Melalui Teori Relief, humor digambarkan sebagai satu cara untuk menenangkan diri seseorang dan memberikan rasa tenang apabila humor itu sampai kepada penerima (Lynch, 2002). Dalam aspek penyelidikan ini humor seperti ini digunakan untuk memberikan emosi yang tenang dalam kalangan murid semasa sesi pengajaran berlangsung. Terdapat kajian menunjukkan bahawa murid berasa selesa dan tenang apabila suasana pembelajaran menyeronokkan dilaksanakan (Abdul Rasid, 2013; Shafee et al. ,2011) dalam hal elemen utama yang terdapat dalam pembelajaran menyeronokkan adalah unsur humor dalam pengajaran guru. Ini disokong lagi dengan kenyataan bahawa salah satu ciri pembelajaran menyeronokkan adalah humor yang dilakukan oleh guru (Kementerian Pendidikan Malaysia, 2019; Amin, 2018).

Seterusnya, Teori Superioriti yang juga merupakan salah satu daripada Teori Humor adalah bagi menjelaskan penggunaan humor yang sengaja mengetawakan seseorang disebabkan kelemahan atau kesilapan yang dilakukan oleh seseorang (Zillman, 1983). Hal ini menjelaskan bahawa seseorang yang diketawakan adalah disebabkan kesalahan atau dijadikan sebagai bahan lawak atau gurauan kepada pelaku humor tersebut. Dalam konteks penyelidikan ini, guru merupakan orang yang mampu untuk melakukan humor ini kerana guru mempunyai kuasa penuh dalam kawalan dan pelaksanaan aktiviti semasa dalam sesi pengajaran. Pengkaji lalu juga ada menjelaskan bahawa seseorang yang menggunakan Teori Superioriti ini adalah orang yang mempunyai kuasa veto dalam suatu keadaan (Wanzer et al., 2006). Namun begitu, pendapat pengkaji lain adalah tidak bersetuju dengan penggunaan humor jenis ini kerana mereka mengkategorikan humor seperti ini adalah jenis humor yang tidak sesuai dalam pengajaran (Asmah, 2008, Wanzer et al., 2006). Terdapat juga kajian yang dilakukan oleh pengkaji tempatan yang lalu menyatakan bahawa masih ada guru yang menggunakan humor yang tidak sesuai dalam pengajaran mereka (Shafee et al., 2011). Penggunaan humor dalam kalangan guru menunjukkan masih terdapat beberapa aspek kelemahan seperti penyalahgunaan kaedah humor yang kurang sesuai dalam pengajaran mereka. Hal ini juga menjadi sebab kepada punca guru yang takut untuk menggunakan humor kerana risau dalam aspek kawalan kelas disebabkan (Abdul Rasid et al., 2012, 2013).

Teori Humor yang seterusnya adalah Teori Ingkongruiti yang menjelaskan humor dihasilkan apabila berlaku percanggahan dan perbezaan makna dengan sesuatu perkara yang disampaikan (Shade, 1996). Hal ini terjadi apabila sesuatu perkara memberikan makna yang berbeza secara mendadak kepada tahap pemahaman seseorang kepada makna asal yang sepatutnya disampaikan. Perkara ini turut dikaitkan dengan tahap perkembangan kognitif kanak-kanak yang mampu memanipulasikan Bahasa dan tingkah laku mereka melalui penggunaan dan pemahaman humor (Shade, 1996). Teori Ingkongruiti adalah dipelopori oleh Immanuel Kant pada tahun 1970 dan juga Schopenhauer pada tahun 1819. Humor ini dihasilkan dalam pelbagai bentuk seperti melalui visual, lisan dan membawa kepada maksud yang berbeza dengan konteks logik. Akhirnya menimbulkan kelucuan daripada humor yang disampaikan kepada penerima. Dalam konteks penyelidikan ini, humor ini dilakukan oleh guru dalam pengajaran dan menyampaikan kelucuan melalui penyampaian makna yang berbeza dalam konteks pengajaran mereka. Pengkaji lalu turut menyatakan bahawa apabila guru melakukan senario yang tidak sesuai dalam kelas iaitu semasa sesi pengajaran akan menimbulkan humor semasa pengajaran tersebut (Norul, 
2017; Farhana, 2018). Maka Teori Ingkongruti adalah kejadian yang berlaku kerana tidak sepadan dengan makna situasi sebenar, tidak logik, bercanggah, mengejut, tidak masuk akal dan tidak menentu (Martin, 2010). Dalam penyelidikan ini, perkara ini diteroka melalui pengajaran yang dilaksanakan oleh guru dalam pengajaran Bahasa Melayu.

Penyampaian humor dalam pengajaran dilakukan dalam pelbagai cara. Salah satu cara yang pernah dinyatakan dalam kajian terdahulu adalah dari aspek kaedah humor secara komunikasi. Kajian lalu menjelaskan bahawa penggunaan humor secara komunikasi dapat menarik perhatian murid semasa dalam pengajaran mereka (Aboudan, 2009). Humor dapat bertindak sebagai satu medium interaksi yang berkesan kepada guru dan murid. Ini dibuktikan juga apabila wujudnya suasana pembelajaran yang selesa dalam kalangan murid untuk berinteraksi dengan guru apabila humor digunakan dalam pengajaran (McCabe, Sprute \& Underdown, 2017). Maka perkara ini menunjukkan bahawa penggunaan humor secara komunikasi boleh menjadi sebagai satu kaedah yang dapat menimbulkan interaksi dalam kalangan guru-murid serta murid-murid.

Hal ini juga ada dijelaskan bahawa kaedah secara komunikasi adalah seperti guru memberikan jawapan yang kreatif, jawapan yang berkaitan dengan realiti kehidupan dan dalam masa yang sama mengaitkan unsur humor dalam perlakuan penyampaian itu (Tews et al., 2015). Perkara ini menunjukkan bahawa kaedah humor secara komunikasi mempunyai pelbagai cara untuk digunakan. Tambahan lagi, humor secara komunikasi adalah humor yang mudah untuk dilaksanakan kerana tidak menggunakan bahan. Penggunaan humor ini juga dapat meningkatkan komunikasi dua hala dalam kalangan murid dan guru (Muhammad \& Rahman, 2017).

Kajian Carl (2018) menunjukkan bahawa penggunaan humor dengan menggunakan bahan adalah satu cara untuk menyampaikan humor dalam pengajaran. Ini dijelaskan apabila terdapat hubungan yang signifikan dalam penggunaan humor sebagai satu bahan dalam kajiannya. Penggunaan humor yang disampaikan melalui video kepada responden dalam kajiannya menunjukkan perbezaan yang ketara berbanding pengajaran yang tidak menggunakan video yang berunsurkan humor. Hal ini menjelaskan bahawa, humor juga boleh disampaikan dengan menggunakan bahan sebagai medium. Pengajaran humor juga boleh dipelbagaikan lagi dengan menggunakan bahan-bahan yang boleh menarik minat murid serta dapat menimbulkan humor dalam pengajaran. Terdapat bukti yang menyatakan bahawa terdapat guru yang menggunakan pelbagai jenis bahan dalam pengajaran dapat menarik perhatian mereka dalam proses pembelajaran (Franklin-Guy \& Schnorr, 2016). Hal ini boleh dikaitkan dengan penggunaan humor secara menggunakan bahan dalam pengajaran guru Bahasa Melayu berdasarkan konteks penyelidikan ini. Beberapa pengkaji juga menunjukkan bahawa terdapat guru yang mempunyai usaha menggunakan humor dalam pengajaran dengan menggunakan bahan seperti kartun, animasi, lukisan atau bahan sastera dalam pengajaran mereka bagi menimbulkan kelucuan kepada murid (Abdul Rasid et al., 2012; 2013; Farhana, 2018; Norul, 2017; Sii \& Mohd Razimi, 2020). Oleh hal yang demikian, humor yang menggunakan bahan dalam pengajaran adalah sesuatu yang bukan asing lagi dalam penggunaan humor dalam pengajaran.

\section{Metod Kajian}

Penyelidikan ini telah dilaksanakan dengan menggunakan kaedah pengumpulan data seperti temu bual, rakaman audio pengajaran dan juga analisis dokumen rasmi dan tidak rasmi para peserta kajian. Penyelidikan menggunakan temu bual sebagai satu kaedah utama untuk mendapatkan data yang mendalam kepada peserta kajian. Hal ini sesuai dengan epistemologi kajian kualitatif iaitu komunikasi merupakan salah satu cara untuk mendapatkan maklumat dan mendalami sesuatu konteks fenomena yang dialami oleh peserta kajian (Creswell,, 2013). Hal ini juga adalah bagi meneroka pengalaman sebenar yang dialami oleh peserta kajian melalui temu bual mendalam bersama mereka. Ini dikatakan bahawa kajian fenomenologi adalah kajian kualitatif untuk memerihalkan sesuatu pengalaman sebenar yang dialami oleh peserta kajian (Merriam, 2009). Maka pengetahuan baharu akan terhasil daripada pernyataan para peserta yang terlibat dalam penyelidikan ini. 
Oleh kerana kajian humor merupakan sesuatu yang subjektif. Maka andaian mengenai fenomena sebenar adalah berdasarkan pemahaman peserta kajian mengenai penggunaan humor yang digunakan oleh mereka dan juga berdasarkan tafsiran daripada penyelidik sendiri. Perkara ini adalah bersesuaian dengan ontologi kajian yang berkaitan dengan paradigma interpretivis iaitu interaksi sosial terhasil melalui pengalaman yang dilalui oleh peserta itu sendiri dan penyelidik menghasilkan makna berdasarkan tafsirannya melalui realiti, pengetahuan dan pengalaman. Ini dinyatakan bahawa realiti boleh dibina, dicipta dan dibentuk (Crouch, 2004) melalui fenomena yang berlaku. Justeru perkara ini akan turut dijelaskan melalui kefahaman daripada peserta kajian itu sendiri melalui realiti sebenar yang dilalui mereka (Taylor \& Bogdan, 1984).

Berdasarkan kepada paradigma yang diterangkan, maka penyelidik telah menggunakan kaedah induktif dalam membentuk tema-tema yang terhasil dalam penyelidikan ini. Ini dinyatakan bahawa kaedah induktif adalah terhasil daripada pembentukan tema yang berulang-ulang melalui elemen dan kategori yang dihimpunkan (Creswell, 2008). Penyelidik juga menghimpunkan dapatan berdasarkan catatan, kata-kata dan pemerhatian berdasarkan perbuatan seseorang (Wilson, 2000). Namun begitu, rakaman secara video tidak dapat dilaksanakan dalam penyelidikan ini lantaran mempunyai halangan daripada etika kajian yang ditelah diberikan oleh Bahagian Perancangan dan Penyelidikan Dasar, KPM. Penyelidik menggantikan rakaman video ini kepada rakaman audio untuk mendapatkan suasana pengajaran sebenar peserta kajian. Maka selepas itu rakaman audio tersebut dipindahkan ke dalam bentuk data verbatim. Dapatan-dapatan ini akan digabungkan dan dirujuk silang dengan dapatan analisis dokumen bersama dengan analisis data verbatim rakaman temu bual bersama para peserta kajian. Bagi menyokong lagi dapatan ini, penyelidik telah melakukan Temu bual berdasarkan bahan rangsangan (TBBR) semasa sesi temu bual bersemuka dilaksanakan untuk memberikan imbas memori kepada para peserta kajian mengenai humor yang telah dilakukan oleh mereka semasa sesi pengajaran. Akhir sekali, semua dapatan akan dimasukkan ke dalam Atlas.ti untuk memudahkan penyelidik membaca berulang kali dan melakukan koding pada setiap data verbatim dan analisis dokumen. Seterusnya, penyelidik menghimpunkan koding-koding kepada elemen-elemen yang sama dan memindahkan kepada himpunan kategori yang bersesuaian bagi membentuk tema-tema dalam penyelidikan ini.

\section{Hasil Kajian}

Dapatan kajian menunjukkan tiga tema yang bersesuaian telah muncul dalam analisis data yang telah dilakukan. Antaranya ialah kaedah humor secara komunikasi, kaedah humor secara bahan, kaedah dan humor secara variasi pengajaran. Ketiga-tiga tema ini adalah terhasil daripada himpunan elemenelemen yang dihimpunkan ke dalam kategori yang bersesuaian untuk menjawab objektif dan soalan kajian dalam penyelidikan ini.

\section{Kaedah humor secara komunikasi}

Tema kaedah humor secara komunikasi menunjukkan bahawa para peserta kajian menggunakan humor berdasarkan dua kategori utama iaitu kaedah humor secara lisan dan kaedah humor secara bukan lisan. Kategori kaedah humor secara lisan menunjukkan bahawa para peserta kajian menggunakan humor dengan menggunakan kaedah bercerita dan pernyataan secara spontan semasa sesi pengajaran mereka. Penyelidik memperoleh dapatan ini berdasarkan analisis yang dilakukan dalam ketiga-tiga kaedah pengumpulan data iaitu temu bual, rakaman audio pengajaran dan analisis dokumen para peserta kajian. Manakala bagi kategori secara bukan lisan menunjukkan para peserta kajian sentiasa menggunakan kaedah seperti aksi humor dan ekspresi muka semasa sesi pengajaran bagi menimbulkan unsur humor. Hal ini didapati penyelidik apabila melakukan rujuk silang dalam ketiga-tiga pengumpulan data bagi setiap peserta kajian dalam penyelidikan ini.

\section{Kaedah humor secara bahan}

Seterusnya, tema kedua dalam dapatan penyelidikan ini adalah kaedah humor secara bahan. Berdasarkan hasil rujuk silang yang dilakukan daripada makna-makna yang ditunjukkan dalam dapatan 
data verbatim temu bual, rakaman audio pengajaran dan analisis dokumen, menunjukkan bahawa dua kategori dominan dalam tema ini. Antaranya ialah kategori bahan grafik dan bahan bukan grafik. Bagi kategori humor secara bahan grafik menunjukkan para peserta kajian telah menggunakan bahan seperti kad imbasan dan lukisan semasa sesi pengajaran mereka bagi menimbulkan suasana humor. Hal ini jelas ditunjukkan apabila rujuk silang dilakukan pada dapatan temu bual, rakaman audio pengajaran dan analisis dokumen para peserta kajian. Manakala dalam kategori humor secara bahan bukan grafik menunjukkan bahawa para peserta kajian menggunakan beberapa elemen iaitu menggunakan alat teknologi, pakaian adiwira, peralatan silap mata, petikan syair, permainan Bahasa dan lirik lagu. Penyelidik mendapati perkara ini apabila melakukan rujuk silang berdasarkan ketiga-tiga pengumpulan data yang dilakukan.

\section{Kaedah humor secara variasi pengajaran}

Tema terakhir yang muncul dalam analisis dapatan dalam penyelidikan ini ialah kaedah humor secara variasi. Terdapat dua kategori yang dominan dalam tema ini iaitu kaedah humor aktiviti jenis statik dan kaedah humor aktiviti jenis tidak statik. Kategori kaedah humor jenis statik menunjukkan bahawa para peserta kajian sentiasa melakukan humor berdasarkan aktiviti didik hibur. Hal ini ditunjukkan oleh semua peserta kajian. Seterusnya dapatan yang diperoleh melalui rujuk silang yang dilakukan dalam ketiga-tiga pengumpulan data serta para peserta, menunjukkan tiga elemen dalam kategori kaedah humor jenis tidak statik iaitu aktiviti permainan, lakonan dan nyanyian.

\section{Perbincangan Kajian}

Dapatan yang diperoleh melalui penerokaan kaedah humor dalam pengajaran guru Bahasa Melayu di sekolah rendah telah menunjukkan bahawa penggunaan kaedah humor oleh guru adalah pelbagai dan sesuai dengan konteks pengajaran guru Bahasa Melayu. Penggunaan kaedah humor secara komunikasi menunjukkan bahawa kaedah humor ini sesuai digunakan dalam pengajaran Bahasa Melayu. Ini turut disokong oleh pengkaji lalu iaitu humor dapat disampaikan melalui secara lisan dan kaedah bukan lisan (Shade, 1996; Asmah, 2008). Walaupun kajian lalu ada menunjukkan bahawa penggunaan kaedah ini banyak digunakan dalam mata pelajaran selain Bahasa Melayu. Penyelidikan ini membuktikan bahawa penggunaan kaedah humor ini turut boleh digunakan dalam mata pelajaran Bahasa Melayu.

Kaedah humor dengan menggunakan bahan juga menunjukkan para peserta kajian kerap menggunakan bahan untuk mewujudkan unsur humor dalam pengajaran mereka. Selari dengan kajian lalu yang menyatakan bahawa humor boleh dihasilkan dengan menggunakan bahan yang sesuai (Shade,1996; Abdul Rasid, 2013; Tay, 2015; Abdul Rasid et al., 2015; Abdul Rasid et al., 2016). Ini disokong lagi dengan pendapat pengkaji lalu bahawa humor melalui bahan membantu guru dalam sesi pengajaran (Norul, 2017 ; Farhanah, 2018).

Akhir sekali, penghasilan humor dalam pengajaran juga boleh dilakukan dengan menggunakan kaedah humor secara variasi pengajaran. Hal ini telah ditunjukkan melalui tema yang diperoleh dalam kajian ini. Kaedah humor boleh dihasilkan melalui pelbagai aktiviti pengajaran. Hal ini turut dipersetujui oleh beberapa pengkaji lalu yang menyatakan bahawa kaedah humor adalah pelbagai dan boleh diaplikasikan oleh para guru melalui aktiviti lakonan, nyanyian, didik hibur, permainan dan tingkah laku guru (Shade, 1996; Zailah, 2012; Deen, 2012; Abdul Rasid et al., 2012; Abdul Rasid et al., 2013, Abdul Rasid et al,. 2016). Oleh hal yang demikian, kaedah humor dalam pengajaran guru Bahasa Melayu masih sesuai digunakan kepada murid pada peringkat sekolah rendah.

\section{Kesimpulan}

Tuntasnya, kaedah humor dalam pengajaran guru Bahasa Melayu di sekolah rendah adalah bukan lagi sesuatu yang asing. Namun begitu penyelidikan ini menunjukkan bahawa, guru Bahasa Melayu masih memerlukan panduan yang jelas dalam menggunakan kaedah humor yang lebih pelbagai dalam pengajaran mereka. Hal ini kerana, perbandingan literatur mengenai kaedah humor dalam pengajaran 
humor masih kurang diperoleh berdasarkan carian penyelidik. Kebanyakan kajian mengenai humor lebih memfokuskan kepada subjek lain dan juga dalam peringkat pengajian yang berbeza. Oleh hal yang demikian, penyelidikan ini diharapkan agar dapat membantu dalam menambahkan literatur terkini mengenai penggunaan humor dalam pengajaran guru Bahasa Melayu dan diharapkan juga dapat mencadangkan kepada pihak Kementerian Pendidikan Malaysia untuk mewujudkan satu panduan penggunaan humor dalam pengajaran khasnya dalam mata pelajaran Bahasa Melayu di sekolah rendah

\section{Rujukan}

Abdul Rasid Jamian, Shamsudin Othman, H. H. (2015). Persepsi Guru Terhadap Penggunaan Kartun Dalam Transformasi Pengajaran Penulisan Karangan Bahasa Melayu. Jurnal Pendidikan Bahasa Melayu, 3, 129-140. https://doi.org/ISSN:2180-4842

Amin Senin, (2018). Melangkah Ke Hadapan, Gerak Kerja \& Fokus Tumpuan KPPM 2018, Kementerian Pendidikan Malaysia.

Abdul Rasid Jamian, Nurul Nadiah Razali, \& Shamsudin Othman. (2016). Pengaplikasian Teknik Didik Hibur Meningkatkan Pencapaian Penulisan Karangan Bahasa Melayu. Jurnal Pendidikan Malaysia, 41(1), 39-45. https://doi.org/10.1002/pol.1951.120070214

Abdul Rasid Jamian, H. (2013). Pelaksanaan pembelajaran menyeronokkan dalam pengajaran dan pembelajaran bahasa melayu. Jurnal Pendidikan Bahasa Melayu, 3, 49-63.

Abd. Samad, R.S., \& Gooi, (2005). Hubungan Antara Iklim Sekolah dengan Kepuasan Kerja guru Sekolah Menengah di Wilayah Persekutuan. Jurnal Pendidikan Universiti Malaya, 25, 163-178

Azriana Abdul Manan, Y. (2011). Humor Dalam Pengajaran dan Pembelajaran Bahasa Melayu. Seminar Bahasa Melayu, 31-38.

Adamson, G., O'Kane, D., \& Shevlin, M. (2005). Students' Ratings of Teaching Effectiveness: A Laughing Matter? Psychological Reports, 96(1), 225-226. doi:10.2466/pr0.96.1.225-226

Asmah Hj. Omar (2008). Eksiklopedia Bahasa Melayu. Kuala Lumpur : Dewan Bahasa dan Pustaka.

Bakar, F. A. (2018). The use of Humour in Teaching And Learning In Higher education. University Of Otago ,Dunedin, New Zealand.

Bahagian Pembangunan Kurikulum (2010). Dokumen Standard Kurikulum Bahasa Malaysia (draf), Putrajaya : Kementerian Pendidikan Malaysia.

Bahagian Pembangunan Kurikulum (2011). Kurikulum Standard Bahasa Malaysia （draf). Putrajaya : Kementerian Pelajaran Malaysia.

Bahagian Pembangunan Kurikulum (2012). Kurikulum Standard Bahasa Malaysia (draf). Putrajaya : Kementerian Pelajaran Malaysia.

Bahagian Pembangunan Kurikulum (2013). Kurikulum Standard Bahasa Malaysia(draf). Putrajaya: Kementerian Pelajaran Malaysia

Creswell, J. W. (2007). Qualitative Inquiry anti 'Research Design. 2nd edition. Thousand Oaks, CA: Sage.

Creswell, J. (2009). Research Design - Qualitative, Quantitative and Mixed Methods Approaches. 3rd edition. Thousand Oaks, CA: Sage Publications.

Creswell, J. W. (2013). Qualitative Inquiry and Research Design: Choosing Among Five Approaches. 3rd edition. Los Angeles: Sage.

Creswell, J. W. (2014). A Concise Introduction to Mixed Methods Research. Thousand Oaks, CA: Sage Publications.

Creswell, J. W., \& Creswell, J. D. (2017). Research design: Qualitative, quantitative, and mixed methods approaches. Sage publications.

Creswell, J. W., \& Poth, C. N. (2017). Qualitative inquiry and research design: Choosing among five approaches. Sage publications.

Frymier, A. B., Wanzer, M. B., \& Wojtaszczyk, A. M. (2008). Assessing Students' Perceptions of Inappropriate and Appropriate Teacher Humor. Communication Education, 57(2), 266-288. doi:10.1080/03634520701687183

Khairuddin Mohamad,Mairdah Alias, Rafiah Daud, Thahir Nurudin, J. (2012). Modul Didik Hibur Dalam Pengajaran dan Pembelajaran Bahasa Malaysia

Malaysia, S. K. P. (2010). Jemaah Nazir dan Jaminan Kualiti. Kementerian Pendidikan Malaysia.

Malaysia, K. P. (1999). Surat Pekeliling Ikhtisas Bil. 3/1999. Penyediaan Rekod. 
Merriam, S, B. (2009). Qualitative Research: A Guide to Design and Implementation. San Fransisco, CA : John Wiley \& Sons, Inc.

Merriam,S. B. (2015). Qualitative Research: Designing, Implementing, and PublishingStudy. In Handbook of Research on Scholarly Publishing and Research Methods, pp. 125-140. Hershey, Pa: IGI Global.

Othman Lebar. (2007). Penyelidikan Kualitatif: Pengenalan Kepada Teori dan Metod. Tanjung Malim: Universiti Pendidikan Sultan Idris.

Othman Lebar. (2015). Penyelidikan Kualitatif. Pengenalan Kepada Teori Dan Metode. Tanjung Malim : Universiti Pendidikan Sultan Idris.

Senin, A. (2018). Melangkah ke Hadapan: Gerak kerja \& Fokus Tumpuan KPPM 2018.

Shaffe Mohd Daud, Roselan Baki, R., \& Sahandri Ghani Hamzah. (2011). Pengaruh Amalan Jenaka Terhadap Pengajaran dan Pembelajaran Murid. Asia Pasific Journal of Educators and Education, 26(1), 125-144.

Tay, M. G. (2015). Pembelajaran menyeronokkan dalam pengajaran dan pembelajaran Bahasa Melayu. Jurnal Penyelidikan IPG KBL, 12, 1-23. https://doi.org/10.1016/j.procs.2014.02.024

Wanzer, M., Frymier, A. B., \& Irwin, J. (2010). An Explanation of the Relationship between Instructor Humor and Student Learning: Instructional Humor Processing Theory. Communication Education, 59(1), 1-18. doi:10.1080/03634520903367238

Zamri Mahamod, \& Magdeline anak Nor. (2012) Penguasaan pengetahuan pedagogi kandungan guru bahasa Iban. GEMA: Online Journal of Language Studies, 12(2), 593-608.

Ziv, A. (1988). Teaching and Learning with Humor. The Journal of Experimental Education, 57(1), 415. doi:10.1080/00220973.1988.10806492

Ziyaeemehr, A., Kumar, V., \& Abdullah, M. (2011). Use and Non-use of Humor in Academic ESL Classrooms. English Language Teaching, 4(3). 